\title{
BEHAVIOR OF L-SHAPED CONCRETE-FILLED STEEL STUB COLUMNS UNDER AXIAL LOADING: EXPERIMENT
}

\author{
Z.Y. Chen ${ }^{1,2,{ }^{*}}$ and Z.Y. Shen ${ }^{3}$ \\ ${ }^{1}$ Lecturer, College of Civil Engineering, Tongji University, Shanghai 200092, China \\ ${ }^{2}$ Key Laboratory of Geotechnical and Underground Engineering of Ministry of Education, \\ Shanghai 200092, China \\ ${ }^{3}$ Professor, College of Civil Engineering, Tongji University, Shanghai 200092, China \\ *(Corresponding author: E-mail: zhiyichen@tongji.edu.cn)
}

Received: 4 January 2009; Revised: 1 June 2009; Accepted: 3 June 2009

\begin{abstract}
Tests were conducted on six L-shaped concrete-filled steel stub columns (CFSSC) and one L-shaped steel hollow column. The nonlinear damage process and the failure mode of the specimens were described. The influences of structural parameters on the axial bearing capacity of L-shaped CFSSCs were investigated. These structural parameters included the width-to-thickness ratio of the steel plate, with or without stiffeners, and the limb length. The experimental results indicated that the confined effect of the steel tube on the infilled concrete was more distinct for an L-shaped CFSSC with a short limb than one with a long limb. For an L-shaped CFSSC with a short limb, the stiffeners may improve the ductility of the specimens to the extent of 1.5 times although they were less effective in improving the bearing capacity. On the other hand, the stiffeners were ineffective in both improving bearing capacity and ductility of the L-shaped CFSSC with a long limb.
\end{abstract}

Keywords: L-shaped concrete-filled steel column; stub column; axial loading; ultimate bearing capacity; ductility

\section{INTRODUCTION}

L-shaped columns are commonly used as corner columns in structural buildings. For instance, the wall thickness in a medium-rise building is relative thin. As a result, the cross-section of beams and columns are usually larger than the wall thickness in a common frame structure. This phenomenon weakens the integrity of the overall space and brings inconvenience to decoration as well. Limb width of a special shaped column (e.g. T-shaped and L-shaped columns) is within 100 to $300 \mathrm{~mm}$, resolving the problem of column projection. Because of asymmetry of two principal axes, the calculation is complicated for an L-shaped column. Besides, additional moment of torsion follows horizontal forces (e.g. wind forces or earthquake actions) due to non-coincidence of torsional center and mass center. In addition, uncertainty of the direction of horizontal forces imposed results in the difficulty of determining orientation of the applied forces in a test. This leads to different properties in terms of bearing capacity, ductility and stiffness for special shaped columns according to different loading directions subjected. Therefore behavior of special shaped column is a difficult issue.

So far, a comprehensive research is carried out for structures with special shaped reinforced concrete columns. Some cities in China, e.g. Tianjin and Guangzhou, have issued local specifications for special shaped reinforced concrete columns[1,2]. The national standard "Technical specification for concrete structures with specially shaped columns" (JGJ149-2006)[3] has also been issued and implemented based on the local specifications. However it is still lack of basic theoretical research on special shaped concrete-filled steel columns (CFSCs). The research results reported are also limited in the world. Of those, Tongji University performed experimental and theoretical research on the seismic behavior of L-shaped CFSCs[4]. However, this kind of members took no consideration of effective confinement of in-filled concrete. In addition to the rectangular ones[5], South China University of Technology carried out experimental study on axial behavior of L-shaped and T-shaped concrete-filled steel tubular stub columns with binding 
bars[6-8]. The current application of special shaped concrete-filled steel structures is known as New China Building in Guangzhou[9,10]. L-shaped and T-shaped concrete-filled steel tubular stub columns with binding bars are adopted for part of columns in the underground structures. In view of the distinguished efficiency of concrete-filled steel structures in economic and social aspects, it is necessary to carry out further research on force and deformation capacities of special shaped CFSCs.

\section{TEST PROGRAM}

\section{$2.1 \quad$ Test Specimens}

In medium- and high-rise buildings, the story height is generally $2.8 \mathrm{~m}$. The limb width of special shaped columns is taken as the wall thickness, generally $200 \mathrm{~mm}$. A scaling factor of 1:2 was considered. The total clear lengths of specimens were $800 \mathrm{~mm}$ and $1200 \mathrm{~mm}$; the limb width was $100 \mathrm{~mm}$; the limb lengths were $200 \mathrm{~mm}$ and $300 \mathrm{~mm}$. In previous concrete-filled stub column experiments, swelling of the outer steel plate was a common failure mode of specimens. It indicates that the outer steel plates are buckled as two sides of the steel plate are fixed-supported and the others are simply- or fixed-supported according to the actual condition. In the national code for design of steel structures [11], the steel plate width-to-thickness ratio under such condition is limited as 60 . Hence designed width-to-thickness ratios of $50(t=4 \mathrm{~mm})$ and $60(t=5 \mathrm{~mm})$ were adopted, for $\mathrm{L}(\mathrm{R}) 2$ series and $\mathrm{L}(\mathrm{R}) 3$ series. The dimension and the cross section of the specimens are summarized in Figure 1 (only those with $200 \mathrm{~mm}$ limb length are presented as space is limited). Detailed parameters are listed in Table 1.

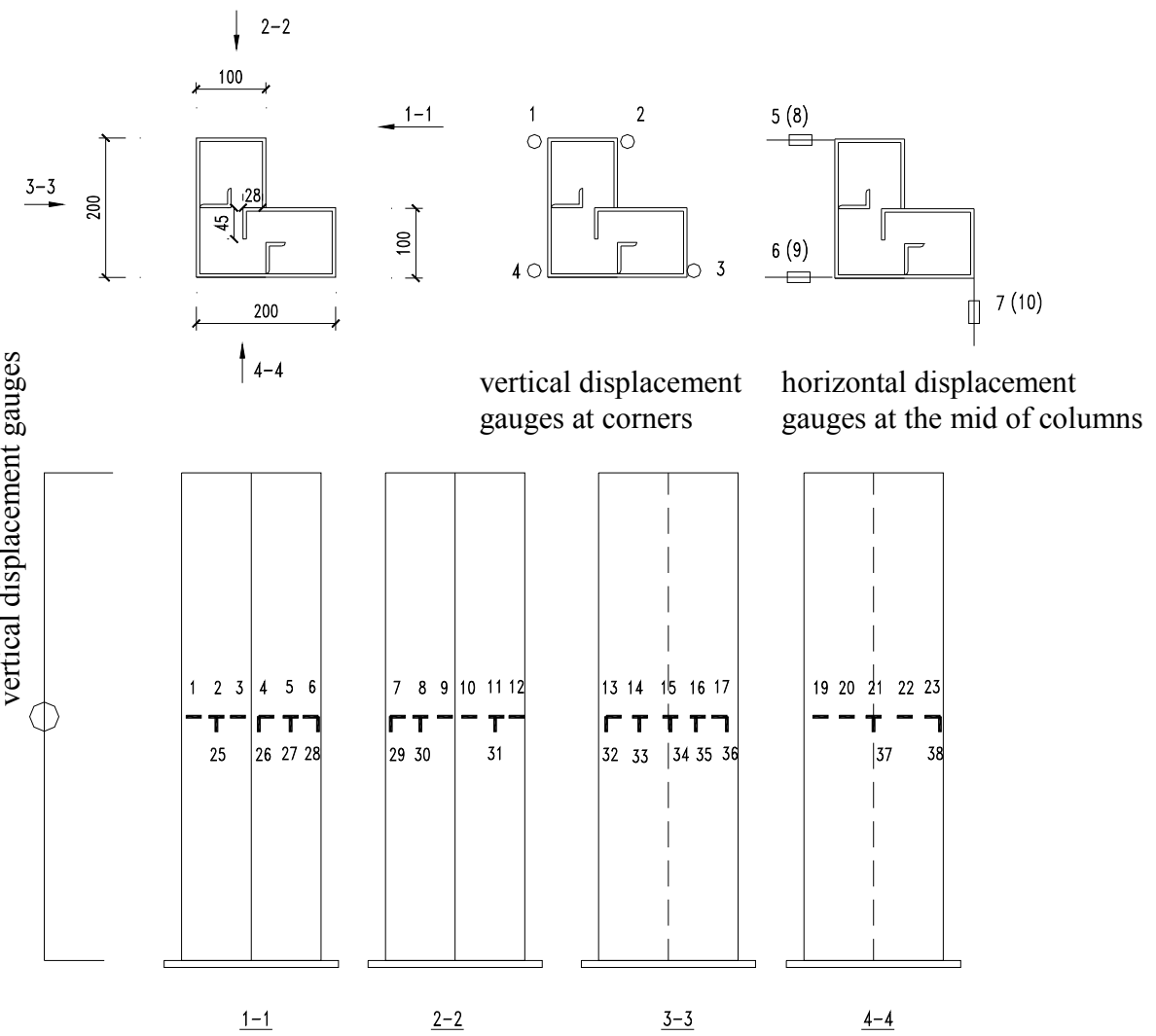

Note: the gauge arrangement is similar for the specimens with limb length of $300 \mathrm{~mm}$.

Figure 1. Specimen Dimensions and Gauge Arrangement 
Table 1. Summary of Specimens

\begin{tabular}{ccccc}
\hline No. & $\begin{array}{c}\text { Limb length, } B \\
(\mathrm{~mm})\end{array}$ & $\begin{array}{c}\text { Total length, } L \\
(\mathrm{~mm})\end{array}$ & $\begin{array}{c}\text { Steel plate thickness, } t \\
(\mathrm{~mm})\end{array}$ & Concrete grade \\
\hline LR2-a & 200 & 800 & $4(3.62)$ & $\mathrm{C} 40$ \\
LR2-b & 200 & 800 & $4(3.62)$ & $\mathrm{C} 40$ \\
L2 & 200 & 800 & $4(3.62)$ & $\mathrm{C} 40$ \\
LR3-a & 300 & 1200 & $5(4.62)$ & $\mathrm{C} 40$ \\
LR3-b & 300 & 1200 & $5(4.62)$ & $\mathrm{C} 40$ \\
L3 & 300 & 1200 & $5(4.62)$ & $\mathrm{C} 40$ \\
LR3-H & 300 & 1200 & $5(4.62)$ & - \\
\hline
\end{tabular}

Note: L represents L-shaped column; R represents stiffened rib in steel tubes; $\mathrm{H}$ represents hollow steel column; the numbers in parentheses are the measured values of steel plate thickness.

\section{$2.2 \quad$ Material Properties}

1) Steel plate properties

The plates for L-shaped concrete-filled steel stub columns were Q235 steel. According to the national standard "Metallic materials-test pieces for tensile testing" (GB6397-86)[12], three test pieces were taken from each steel plate of different plate thickness along and perpendicular to the rolling direction. Tensile test was performed in the lab of material mechanics, Tongji University. The obtained results are listed in Table 2.

Table 2. Tensile Test Results

\begin{tabular}{ccccc}
\hline Coupon & $\begin{array}{c}\text { Yield strength } \\
\mathrm{MPa}\end{array}$ & $\begin{array}{c}\text { Tensile strength } \\
\mathrm{MPa}\end{array}$ & $\begin{array}{c}\text { Elastic modulus } \\
\times 10^{5} \mathrm{MPa}\end{array}$ & $\begin{array}{c}\text { Elongation } \\
\%\end{array}$ \\
\hline $4 \mathrm{~mm}$ & 310 & 465 & 2.030 & 24 \\
$5 \mathrm{~mm}$ & 295 & 442 & 2.117 & 37 \\
\hline
\end{tabular}

\section{2) Concrete properties}

The concrete grade was C40 in the test. The ordinary portland cement was used; the maximum grain size of crushed stones was $20 \mathrm{~mm}$; common medium sand was used. All the specimens were casted in one day. At the same time, three $150 \times 150 \times 150 \mathrm{~mm}$ cubic coupons were fabricated and were cured under the same conditions of the specimens. After curing period of 28 days, cube compressive strength tests were conducted according to the national standard "Standard for test method of mechanical properties on ordinary concrete"(GB/T 50081-2002)[13]. The average cube compressive strength, $f_{c u}$, was $60.1 \mathrm{MPa}$ as obtained from the tests. The axial compressive strength, $f_{c k}$, which was converted from $f_{c u}$ was $45.7 \mathrm{MPa}$.

\subsection{Test Setup and Gauge Arrangement}

Axial compressive tests were conducted by a 500 ton test machine in the static experimental laboratory, Tongji University. The gauge arrangement was shown in Figure 1. At the four corners of each specimen, four vertical displacement gauges were installed to record the total vertical deformation of the column. Three horizontal displacement gauges were installed at the middle and top of the column, respectively, to measure the torsion angle of the cross sections. Strain gauges numbered from 1 to 23 (18 was not present) were used to inspect circumferential strain of the steel tube while strain gauges numbered from 25 to 38 were used to inspect its longitudinal strain. 


\section{$2.4 \quad$ Loading Sequence}

Prior to imposing axial compressive force, the specimen was aligned to the geometrical center. Then, it was aligned physically according to the values of vertical displacement and longitudinal strain. Loading should not be formally imposed until instruments worked normally under the preloading (about 40 percent of the ultimate load estimated). Stepped loading was performed based on the estimated ultimate load. Before 50 to 60 percent of the estimated ultimate load, the stepped loading imposed was $1 / 15$ of the estimated ultimate load. An interval time of two minutes was taken at every two loading levels in order to let deformation fully developed. After that, the nonlinear behavior of specimens was distinct. Consequently, a data acquisition system was used for digital signal acquiring and processing until specimen failure.

\section{TEST PROCESS AND ANALYSIS OF TEST RESULTS}

\subsection{Test Damage Process and Failure Mode}

The damage process were almost analogous for all specimens, basically experiencing several phases such as elastic phase, small swelling at steel plate of the limb, obvious swelling at steel plate of the limb, and remarkable strength deterioration. The failure mode of the specimens is related to the limb length, with or without stiffeners and with or without infilled concrete.

For L-shaped CFSC with limb length of $200 \mathrm{~mm}$, limb width of $100 \mathrm{~mm}$, and relative small plate width-to-thickness (LR2-a and LR2-b), minor flaking of the mill scale was visually identifiable, which was accompanied by a continuous noise, when the imposed load is about 90 percent of the estimated ultimate load. As the imposed load was increased, the onset of web buckling was evident. As the imposed load was increased toward the ultimate load, two to four buckling waves occurred. The deformation increased sharply. The test was then stopped.

For L-shaped CFSC with limb length of $300 \mathrm{~mm}$, limb width of $100 \mathrm{~mm}$, and relative large plate width-to-thickness (LR3-a and LR3-b), the test process was similar to the L(R)2 series specimens during the elastic phase. As the imposed load was increased toward the ultimate load, the first occurrence of the swelling was locally at the concave face. Then swelling occurred at every faces. The deformation increased sharply, especially at the convex face. However no buckling was observed at the ends of the limbs.

On the counterpart, local buckling occurred for the L-shaped CFSC without stiffeners (L2 and L3). With the increase of the applied load, buckling phenomenon became more and more obvious. The specimen failed when the out plane deformation reached some extent.

The failure mode of the L-shaped hollow steel column possessed the following features: (1) if a half wave occurred in one of the two big faces, then a total wave must occur in the other big face, where nodal line was formed in the position of the stiffener; (2) at the bottom of the column, two limbs, which were combined as a plate member, formed one half wave in the longitudinal direction; and (3) at the top and the medium of the column, the failure mode was analogous to the rectangular hollow steel tubes. That is, two counter plates swelled, and the other two counter plates sunk. Therefore, it can be concluded that due to the lack of the lateral supporting of concrete the hollow steel tube tends to local buckling and the ultimate force decreased sharply despite the small width-to-thickness ratio resulted by the stiffeners. 
Figure 2 plots the typical failure modes for L-shaped CFSCs. The ultimate bearing capacities, $N_{u}{ }^{\text {exp }}$, are listed in Table 3, where $f_{y}$ represents yield strength of steel plate, $A_{c}$ and $A_{s}$ represent the cross section area of concrete and steel, respectively.

Table 3. Ultimate Bearing Capacities of L-shaped CFSCs

\begin{tabular}{cccccc}
\hline No. & $\begin{array}{c}f_{c k} \\
\mathrm{MPa}\end{array}$ & $\begin{array}{c}A_{c} \\
\mathrm{~mm}^{2}\end{array}$ & $\begin{array}{c}f_{y} \\
\mathrm{MPa}\end{array}$ & $\begin{array}{c}A_{s} \\
\mathrm{~mm}^{2}\end{array}$ & $\begin{array}{c}\boldsymbol{N}_{\boldsymbol{u}}^{\text {exp }} \\
\mathrm{kN}\end{array}$ \\
\hline LR2-a & 45.7 & 26087 & 310 & 3913 & 2568 \\
LR2-b & 45.7 & 26087 & 310 & 3913 & 2892 \\
L2 & 45.7 & 26836 & 310 & 3164 & 2460 \\
LR3-a & 45.7 & 43190 & 295 & 6810 & 4024 \\
LR3-b & 45.7 & 43190 & 295 & 6810 & 3908 \\
L3 & 45.7 & 44133 & 295 & 5867 & 3708 \\
LR3-H & -- & -- & 295 & 6810 & 1604 \\
\hline
\end{tabular}

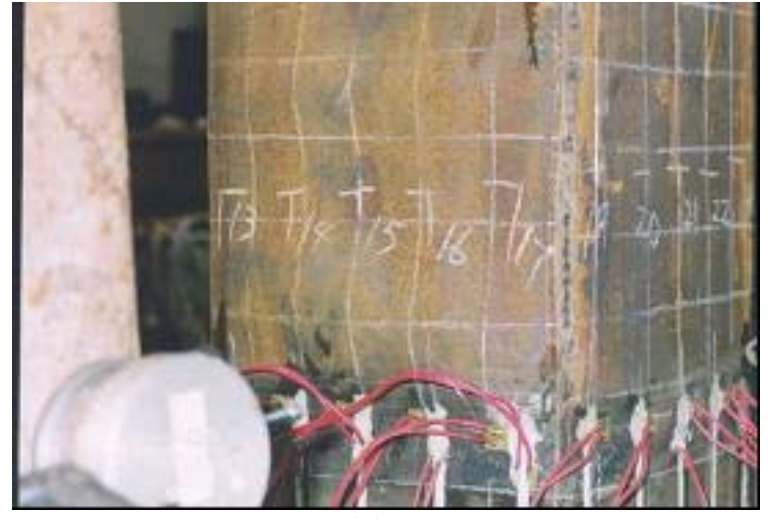

(a)

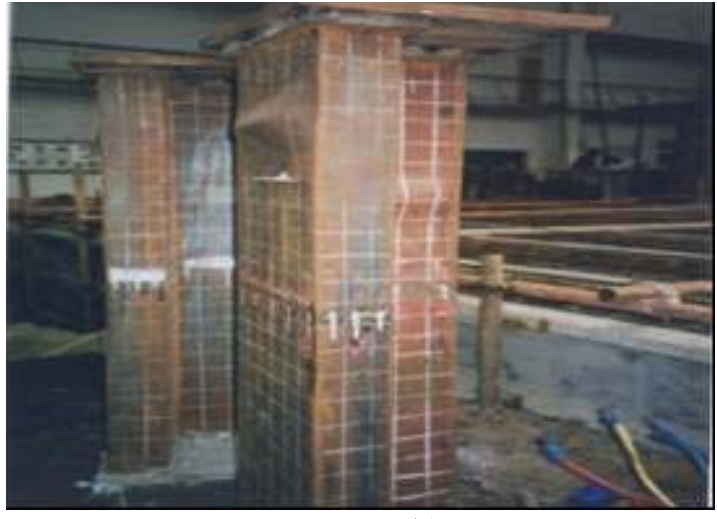

(b)

Figure 2. Failure Modes: (a) LR2-a; (b)LR3-a

\subsection{Analysis and Discussion of Test Results}

1) Force versus vertical displacement ratio curves (No.1 4 vertical displacement gauges)

The forces versus vertical displacement ratio relationships are shown in Figure 3. From Figure 3(a), it is found that ultimate bearing capacity differs in LR2-a and LR2-b due to the loading eccentricity. The force verses vertical displacement ratio curves indicate that: (1) prior to the 70 percent ultimate force, all curves were closely analogous with each other and almost kept straight (in an elastic state); (2) the first inclination occurred due to the development of plastic region; (3) as the imposed load reached 90 percent of the ultimate load, plastic flow occurred. Slight swelling of steel plates was visually observed due to the compressing of the concrete. Vertical deformation increased severely, and the second inclination occurred; (4) as vertical displacement ratios of LR2-a and LR2-b approximated $4312 \times 10^{-6}$ and $4676 \times 10^{-6}$ respectively, peak values of the specimens were reached; (5) from then on, concrete cracked and expanded and steel tub bulged. The relationships of $\mathrm{L}(\mathrm{R}) 2$ specimens fell gradually and formed a relative long horizontal segment at 68 to 78 percent of ultimate force due to the bonding effect of the stiffener.

L2 reached the ultimate force when vertical displacement ratio was $3892 \times 10^{-6}$. Without stiffeners, partly due to the small flexural rigidity of the steel plates, it was difficult to control concrete plastic flow. Thus the curve started to ramp when the peak value was reached. With the increase of the deflection of the steel tube, lateral stress increased rapidly. This meant the constrained effect on the concrete core was enhanced. As a result, the slope of the curve decreased when imposed load was $1744 \mathrm{kN}$. It showed good ductility of the specimen. 

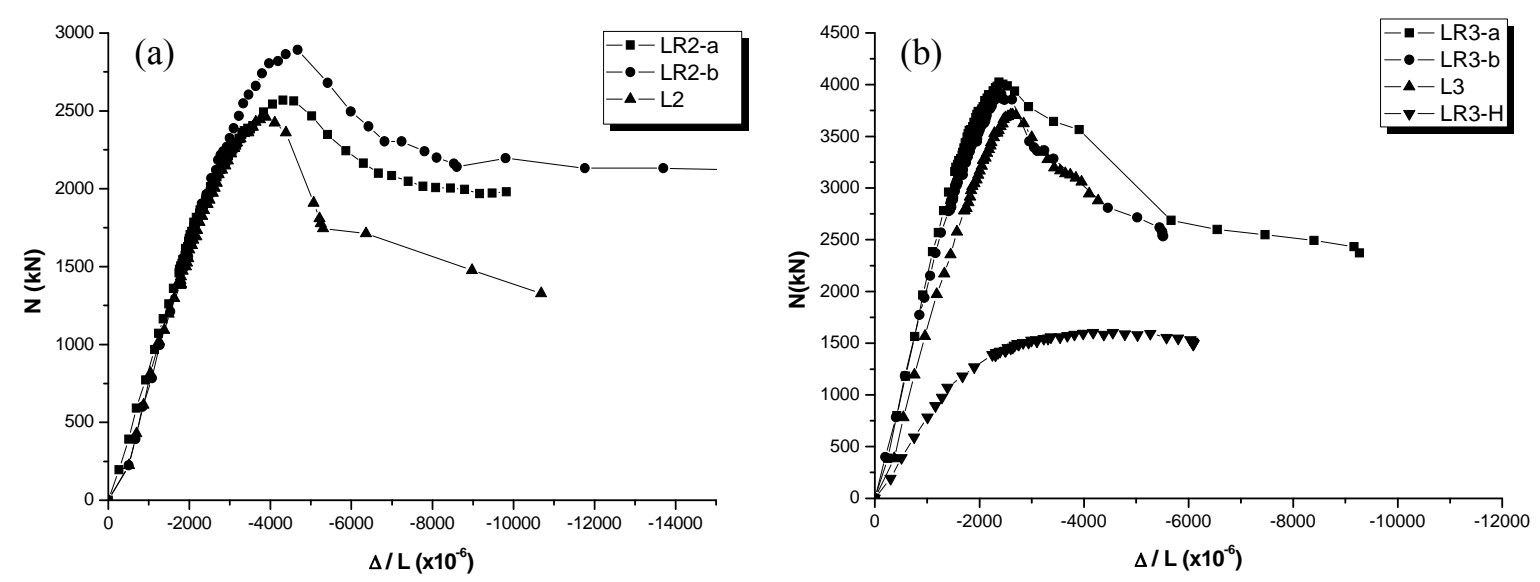

Figure 3. Force Versus Average Vertical Displacement Ratio Curves:

(a) L(R)2 Series; (b) L(R)3 Series

It can be concluded that for an L-shaped CFSSC with a short limb, the stiffeners may improve the ductility of the specimens although they are less effective in improving the force capacity.

As seen from Figure 3(b), it is found that the force-average vertical displacement ratio curves of LR3-a and LR3-b were almost analogous. The relationships indicated that: (1) prior to the 80 percent ultimate force, all curves almost kept straight. The slope and ultimate force of L3 were relative smaller than those of LR3-a and LR3-b; (2) local buckling of the steel plate occurred since the plate width-to-thickness ratio was large. Especially for L3, its maximum value of the width-to-thickness ratio was 65 , exceeding the limit value of 60 for uniaxial compressive plate with two edges fixed. The ultimate force was reached as the displacement ratio was $2500 \times 10^{-6}$; (3) the relationships of three specimens were almost analogous and forms a relative long horizontal segment at 60 to 70 percent of the ultimate force. It showed good ductility of the specimen.

It can be concluded that the stiffeners are ineffective in both force capacity and ductility of the L-shaped CFSC with a long limb.

Comparison of force verses vertical displacement ratio curves between the hollow steel tube and concrete-filled steel columns indicated that the latter present better stiffness, strength and stability.

\section{2) Longitudinal strain of steel tube (No.25 38 strain gauges)}

To study the longitudinal strain and development of plastic region on the cross section, force-average longitudinal strain curves are plotted in Figure 4. As seen from two plots, it is found that the average longitudinal strain of $\mathrm{L}(\mathrm{R}) 2$ specimens was about $2500 \mu \varepsilon$ as the imposed load reached the ultimate force. For LR2-b, it was $4000 \mu \varepsilon$. The descending branch of the force-average longitudinal strain curves were gradually. As the imposed load reached ultimate force of $L(R) 3$, the average longitudinal strain was about $2000 \mu \varepsilon$. Passing over the peak value, slopes of the curves decreased sharply without the horizontal segment. This indicated that the stress distributed uniformly in L(R)2 specimens. Deformation fully developed. However the stress was distributed non-uniformly in $L(R) 3$ specimens. Limb ends sustained most of the external force. At the ultimate force, part of the cross section of these specimens did not yield or just reached the yield region. 

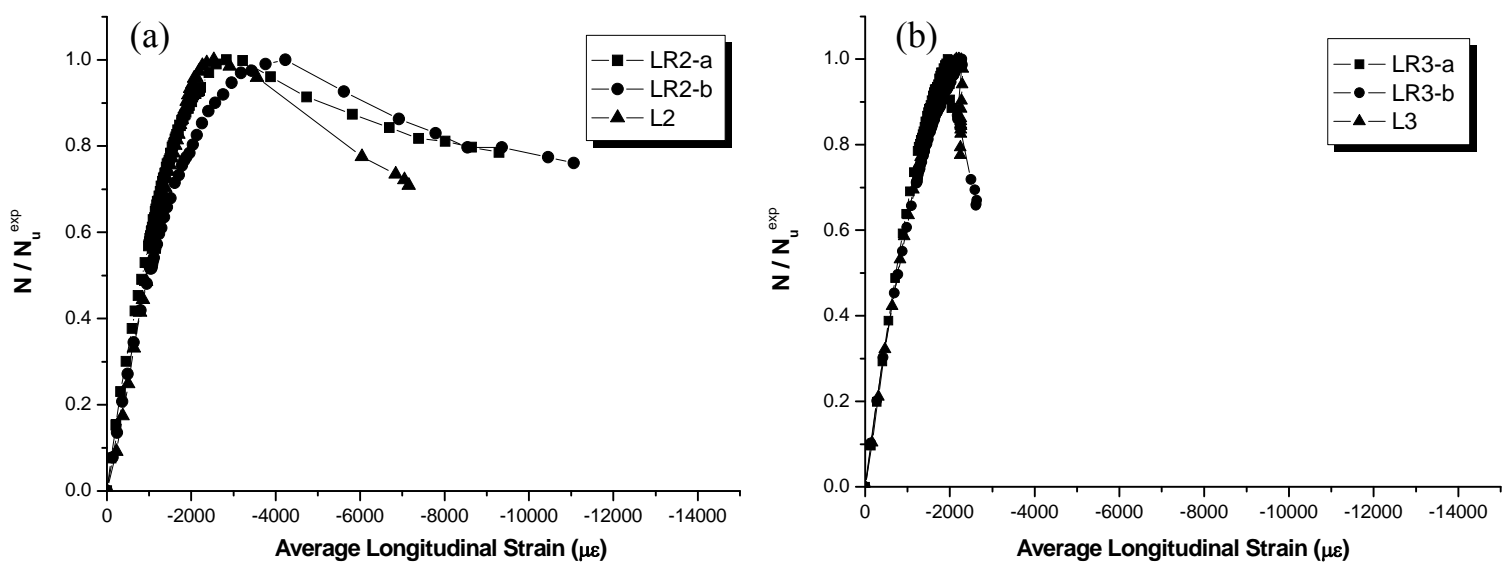

Figure 4. Force Versus Average Longitudinal Strain Curves: (a) L(R)2 series; (b) L(R)3 series

3) Lateral strain of steel tube (No.1 23 strain gauges)

In order to investigate the restrained effect of the steel tube on the concrete during different loading phase, experimental results are organized in the manner of Figures 5-7. Lateral strains of steel tubes were plotted against $0.2,0.4,0.6,0.8$, and $1.0 N_{u}$. The number in the abscissa represents the serial number of strain gauges.
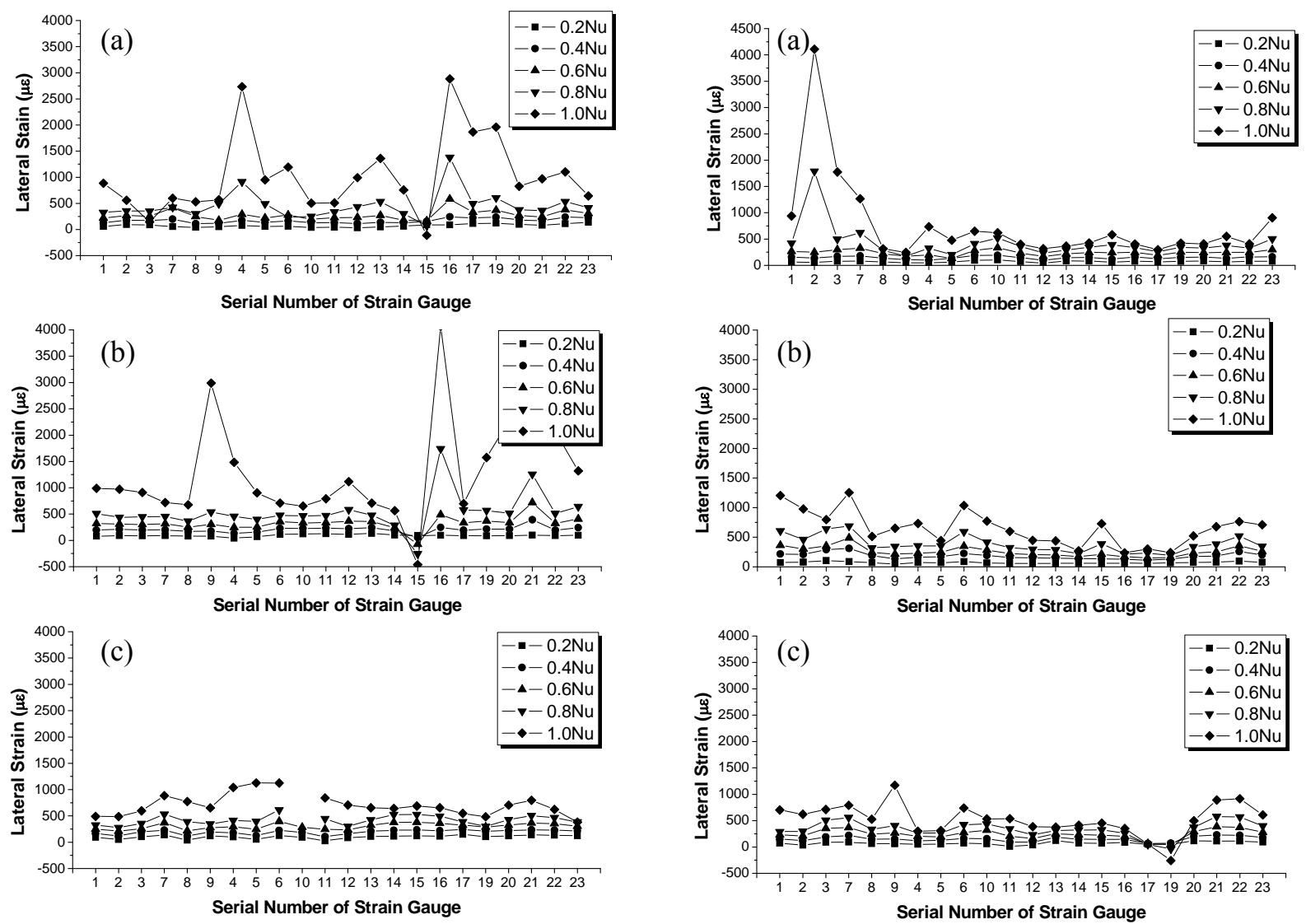

Figure 5. Lateral Strain of Steel Tubes for L(R)2 Series: (a) LR2-a; (b) LR2-b; (c) L2

Figure 6. Lateral Strain of Steel Tubes for L(R)3 Series:(a) LR3-a; (b) LR3-b; (c) L3

The stress distributed uniformly on the cross section prior to $0.8 N_{u}$. At final loading phase, lateral stresses in the steel tube increased due to the occurrence of the concrete plastic flow as well as the compressive effect on the steel tube. The restrained force developed, which was one of the factors that increased the concrete strength. 
4) Torsion of the cross section (No.5 10 lateral displacement gauges)

Due to non-coincidence of torsional center and mass center, additional moment of torsion was evidently yielded by the secondary moment resulted from a vertical force and initial defects and initial eccentricities.

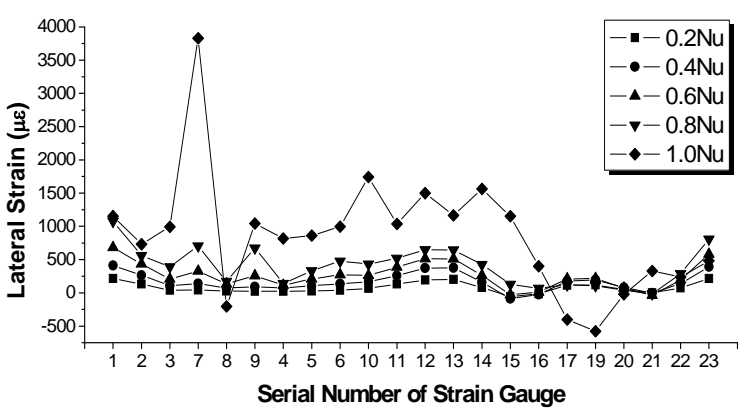

To investigate the torsional parameters of L-shaped CFSCs, horizontal displacement

Figure 7. Lateral Strain of Steel Tubes for LR3-H gauges were placed at the middle and the top of the specimens to record horizontal displacement. Then the torsional angle of the limb in Figure 8 was calculated as: displacement difference between horizontal displacement gauges at the same horizontal plane was divided by the length of the section side.

From Figure 8, it can be seen that the torsional angles of L-shaped CFSCs were small, within the range of 1 to $2 \times 10^{-3}$ radian. The torsional directions of the cross sections at the top and the middle of the column were basically reverse.
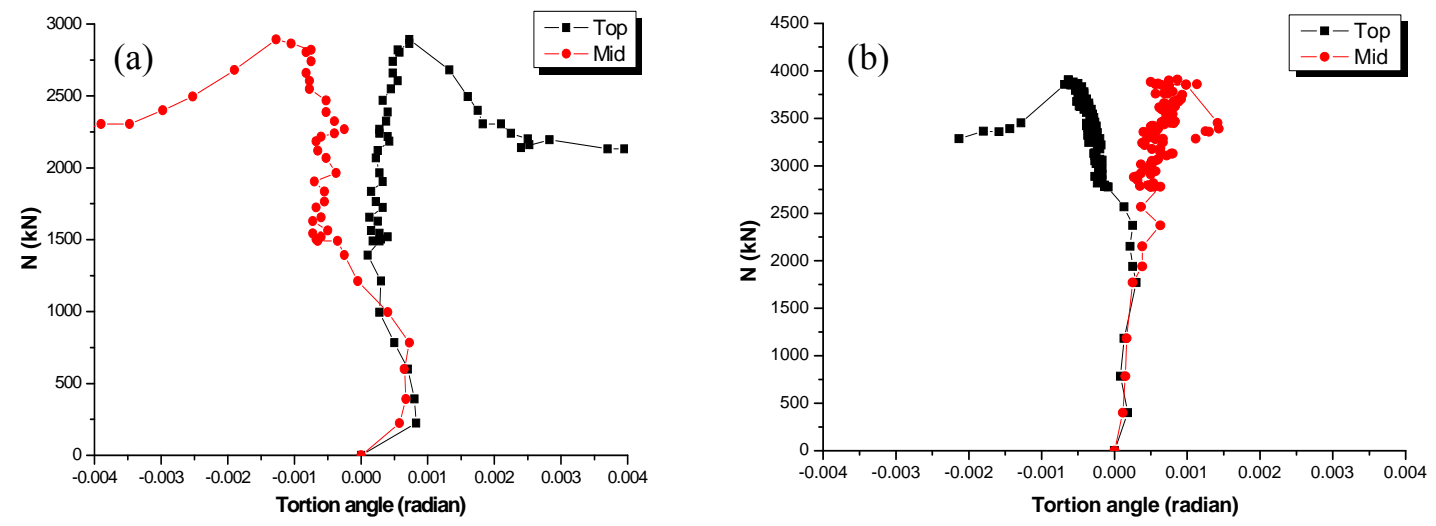

Figure 8. Torsional Angles of the Cross Section: (a) LR2-b; (b) LR3-b

\section{CONCLUSIONS}

Based on the failure process and analysis of the experimental results, the following conclusions are drawn:

(1) In view of the failure mode, the stiffened specimens with short limbs failed in the manner of compressive fracture. Several buckling waves occurred in the middle of the column along the longitudinal direction. As seen from the longitudinal strain curves of the steel tube, the cross section sustained external forces uniformly. Full cross section yielded at the ultimate load. Thus force capacity was improved greatly. For the specimens with long limbs, local buckling only occurred at the top of the column. Parts of steel tube yielded at the ultimate load. In view of this, it is suggested that the limb length-to-width ratio should not be larger than 2.0 in practices for CFSSC with different configurations in order to obtain full bearing capacity. 
(2) As seen from the force versus average vertical displacement ratio curves, curves kept straight prior to 70 to 80 percent of the ultimate load. For an L-shaped CFSSC with a short limb (LR2-a, b), the stiffeners may improve the ductility of the specimens although they are less effective in improving the force capacity. On the other hand, the stiffeners are ineffective in both force capacity and ductility of the L-shaped CFSSC with a long limb (LR3-a, b).

(3) Compared to $L(R) 2$ specimens, local buckling concentrated in the middle and the top of $L(R) 3$ specimens due to the large width-to-thickness ratio. Stress in the middle of the column plate was lower than the yield strength. Material strength could not fully used. This was also one of the main factors that increased the force capacity of the specimens.

(4) The lateral stress curves had several peaks, i.e. buckling waves, for specimens with short limbs. For specimens with long limbs and without stiffeners, the lateral stress was relatively distributed uniformly. This test phenomenon indicated confined effect of the steel tube on the infilled concrete was more distinct for an L-shaped CFSSC with a short limb than one with a long limb, and with stiffeners than without stiffeners.

(5) The torsional angles of L-shaped CFSSCs are small, within the range of 1 to $2 \times 10^{-3}$ radian.

\section{ACKNOWLEDGMENTS}

The research has been supported by the National Natural Science Foundation of China (Grant No. 50908169), the Specialized Research Fund for the Doctoral Program of Higher Education (Grant No. 200802471095), and the Shanghai Pujiang Program. All supports are gratefully acknowledged.

\section{REFERENCES}

[1] Committee of Urban-rural Development of Tianjin, "Technical Specification for Lightweight Framed Structures with Special-shaped Reinforced Concrete Columns of Large Bay Dwelling House (DB29-16-98)", China Architecture \& Building Press, 1998.

[2] Guangdong Association for Engineering Construction Standardization, "Design Specification for Special-shaped Reinforced Concrete Columns (DBJ/T15-15-95)", Technology and Standardization, 1995.

[3] Ministry of Housing and Urban-Rural Development of the People's Republic of China, "Technical Specification for Concrete Structures with Specially Shaped Columns (JGJ 149-2006)", China Architecture \& Building Press, 2006.

[4] Wang, D. and Lv, X.L., "Experimental Study on Seismic Behavior of Concrete-filled Steel T-section and L-section Columns", Journal of Building Structures, 2005, Vol. 26, No. 4, pp. 39-106.

[5] Cai, J. and He, Z.Q., “Axial Load Behavior of Square CFT Stub Columns with Binding Bars", Journal of Constructional Steel Research, 2006, Vol. 62, No. 5, pp. 472- 483.

[6] Chen, D.M., "Basic Mechanics Study on Behavior of Special-shaped Concrete-filled Steel Tubular Columns with Binding Bars", South China University of Technology, 2000.

[7] Li, Z.J., Cai, J., Tan, Z.D. and Chen, D.M., "Experimental Research on Behavior of Special-shaped Concrete-filled Steel Tubular Columns with Binding Bars", Engineering Mechanics, 2001, Vol. A02, pp. 124-129. 
[8] Long, Y.L. and Cai, J., "Experimental Investigation into Axial Compressive Behavior of L-shaped Concrete-filled Steel Tubular Stub Columns with Binding Bars", Journal of South China University of Technology (Natural Science Edition), 2006, Vol. 34, No.11, pp.87-92.

[9] Chen, Z.J. and Lin, Z.F., "Dynamic Analyses of Test Model for New China Building in Guangzhou", World Information On Earthquake Engineering, 2002, Vol. 18, No. 3, pp.102-105.

[10] Chen, Z.B., Chen, X., Ye, Q.Y. and Luo, C., "Structural Design of Guangzhou New China Mansion", Journal of Building Structures, 2000, Vol. 21, No. 3, pp. 2-9.

[11] Ministry of Housing and Urban-Rural Development of the People's Republic of China, "Code for Design of Steel Structures (GB 50017-2003)", China Architecture \& Building Press, 2003.

[12] China State Bureau of Standards, "Metallic Materials-test Pieces for Tensile Testing (GB6397-86)”, China Architecture \& Building Press, 1998.

[13] Ministry of Housing and Urban-Rural Development of the People's Republic of China, "Standard for Test Method of Mechanical Properties on Ordinary Concrete (GB/T 50081-2002)", China Architecture \& Building Press, 2003. 